\title{
Air pollutant emissions from economic sectors in China: a linkage analysis
}

\author{
Yuan Wang ${ }^{1}$, Nan Lai ${ }^{1}$, Guozhu Mao ${ }^{1}$, Jian Zuo ${ }^{2}$, John Crittenden ${ }^{3}$, Yi Jin ${ }^{4}$, Juan \\ Moreno-Cruz ${ }^{5}$
}

\begin{abstract}
We employ the Hypothetical Extraction Method (HEM) using the the Input-Output (IO) table and emissions data for China in 2010 to map flows of embodied air pollutant emissions. The results showed that the Construction sector (28.21\% of $\mathrm{SO}_{2}, 29.84 \%$ of $\mathrm{NO}_{\mathrm{x}}, 34.74 \%$ of Soot, $39.62 \%$ of Dust) dominates other sectors in terms of demand embodied emissions, followed by the Machinery Manufacturing (20.63\% of $\mathrm{SO}_{2}, 19.20 \%$ of $\mathrm{NO}_{\mathrm{x}}, 18.03 \%$ of Soot, $24.05 \%$ of Dust) and Service sectors (13.86\% of $\mathrm{SO}_{2}, 13.18 \%$ of $\mathrm{NO}_{x}, 12.67 \%$ of Soot, $10.09 \%$ of Dust). The Power \& Gas $(48.98 \%, 60.45 \%$ and $30.66 \%$ of $\mathrm{SO}_{2}, \mathrm{NO}_{\mathrm{x}}$, Soot emissions, respectively), Nonmetal Products (26.87\% of Dust) and Metal Mining, Smelting \& Pressing (29.51\% of Dust) sectors, which provide electricity, steel, and cement and so on, were significant contributors to direct air pollutant emissions. The largest inter-sector flow of $\mathrm{SO}_{2}$ emissions was from the Power \& Gas sector to Construction sector (2301.3kt). Meanwhile, the largest inter-sector flow of industrial dust emissions was from Nonmetal Products to Construction sector $(1560.0 \mathrm{kt})$. From the regional perspective, Hebei and Shanxi provinces were the main sources of output emissions in China, with their industrial output dominated by energy (mainly coal) and heavy industry. Based on our findings, we suggest a few strategies to control air-pollution in China: (1) designing differentiated sectoral control strategies by considering supply chain; (2) establishing a regional responsibility sharing mechanism for air pollutants emissions; and (3) using pricing mechanisms to implement internalize the emissions along the supply chain.
\end{abstract}

\section{Keywords}

Input-output analysis, HEM, air pollutant, China 


\begin{tabular}{|ll|}
\hline Nomenclature \\
Acronyms & \\
HEM & Hypothetical extraction method \\
MEIC & Multi-resolution emission inventory for china \\
MRIO & Multi-regional Input-output Model \\
DE & Demand emission \\
NBLE & Net backward linkage emission \\
OE & Output emission \\
NFLE & Net forward linkage emission \\
IE & Internal emission \\
NTE & Net transferred emissions \\
ME & Mixed emission \\
DEI & Direct emissions intensity \\
TEI & Total emissions intensity \\
RLI & Regional linkage index \\
& \\
Symbols & \\
A & Technical coefficient matrix \\
L & Leontief inverse matrix \\
X & Total output vector \\
Y & Final demand vector \\
A & Matrices of the direct requirement coefficient that measure domestic products \\
A & Matrices of the direct requirement coefficient that measure imported products \\
W & Total pollutant emission \\
M & Vector of imports \\
E & Vector of exports \\
S & Target sector \\
C & The total pollutant emissions related to the hypothetical productive relationships \\
$\Delta$ & The elements of the Leontief inverse matrix \\
\hline
\end{tabular}

\section{Introduction}

Rapid urbanization has demanded a large quantity of energy and materials (Yuan et al., 2013). Severe air pollution associated with the rapid urbanization is a pressing issue in rapidly developing countries or regions (Zhao et al., 2013). These countries and regions rely heavily on energy-intensive industries and consequently experience air quality issues due to the large consumption of fossil fuels (Wei et al., 2014). Two-thirds of the most-polluted cities in the world are located in China (Fujii et al., 2013). According to official statistics in 2015, the annual average $\mathrm{PM}_{2.5}$ concentration in 338 core cities was $43 \%$ higher than the national standard (Chen, 2016).

The main sources of atmospheric PM are direct energy combustion, industrial process emissions and atmospheric pollutant reactions. Industrial emissions of Dust and Soot constitute direct sources of PM. Local $\mathrm{SO}_{2}$ emissions are the main sources of $\mathrm{SO}_{4}{ }^{2-}$ in $\mathrm{PM}_{2.5}$ (Yao, et al., 2002). The formation of sulfate from $\mathrm{SO}_{2}$ is due to the coexistence of $\mathrm{NO}_{x}$ (Ma, et al., 2008; He, et al. 2014). Currently, official statistics are only available for $\mathrm{SO}_{2}, \mathrm{NO}_{\mathrm{x}}$, Soot and Dust ${ }^{1}$ emissions in China. The Chinese government has regularly published data on these four air pollutant emissions (National pollution census, 2011). Unfortunately, there is no official emission data on $\mathrm{PM}_{2.5}$ emissions. It is well recognized that $\mathrm{SO}_{2}, \mathrm{NO}_{\mathbf{x}}$,

\footnotetext{
${ }^{1}$ The main difference between soot and dust is the size of the particle: if the diameter is less than 0.1 micrometers, then the particle is soot; if it is greater than 0.1 micrometer, then it is dust.
} 
Soot and Dust emissions are main sources of $\mathrm{PM}_{2.5}$. Therefore, this research aims to study the $\mathrm{SO}_{2}, \mathrm{NO}_{\mathrm{x}}$, Soot and Dust emission flows among economic sectors and regions, as precursors of $\mathrm{PM}_{2.5}$. The results could be useful for policy-making processes to control the haze pollution.

Energy consumption and pollutant emissions during the manufacturing process are known as embodied energy and embodied emissions (Peters \& Hertwich, 2006). There are several studies on embodied emissions derived from economic activities. Studies on the Chinese context have mainly focused on the embodied $\mathrm{CO}_{2}$ emissions within the supply chain (Chang, 2015; Chen et al., 2013; Mi et al., 2015; Skelton et al., 2011; Wang et al. 2013; Feng et al. 2014; Singh et al. 2015; Muangthai, 2016). Recently, embodied air pollutant emissions flows between producers and consumers were also evaluated. From embodied emissions perspective, Huo et al. (2014) found the equipment, machinery, and devices manufacturing and construction sectors contributed to more than $50 \%$ of $\mathrm{SO}_{2}, \mathrm{NO}_{\mathrm{x}}, \mathrm{PM}_{2.5}$, and VOC emissions in 2010 respectively according to multi-resolution emission inventory for China (MEIC).

Input-Output models have been widely employed in embodied emissions research field. Single-regional input-output model (SRIO) is a common tool to study inter-sectoral embodied emissions, while Multiregional Input-Output model (MRIO) is widely adopted to examine inter-regional embodied emissions. Based on an MRIO model, Skelton (2011) revealed that the Construction and Service sectors were the major contributors of $\mathrm{CO}_{2}$ emissions in the global production system. Multi-region analysis has also been employed to investigate the ecological and water footprint of economic activity (Ewing et al. 2014; Zhou et al. 2016)

We used the Hypothetical Extraction Method (HEM), a well-recognized method to measure the importance of economic linkages, to identify flows of the embodied air pollutant emissions. In essence, HEM determines the importance of one sector and its impact on the entire industrial system by comparing the outputs of other sectors before and after the hypothetical extraction of the sector from the production chain (Schultz, 1977). HEM provides a useful method to reveal the importance of a sector for other sectors that require its output as an input (forward linkages); and for sectors that supply inputs into its production process (backwards linkages).

HEM was initially proposed by Strassert (1968) and later reformulated by Cella (1984) and Clements (1990). It can be used to estimate the possible effects of shutting down a particular establishment or other identifiable segment of an economy (Dietzenbacher, 2013). These include individual sectors such as agriculture sector (Cai and Leung, 2004) and construction sector (Song et al., 2006). The first application of HEM-based resources accounting intended to attribute the responsibility of water transfer to intermediate consumers (Durate et al., 2002). HEM has been adopted in previous studies in the fields of environment and resources. The main focuses of these studies include: measuring $\mathrm{CO}_{2}$ emissions of inter-sectoral or inter-regional linkages (Wang et al., 2013; Zhao et al., 2015; Ali 2015; Zhao et al., 2016), measuring energy linkages (Guerra and Sancho, 2010), and estimating inter-temporal direct and indirect water productivity (Blanco and Thaler, 2014). However, there is no study to examine atmospheric pollutant emissions via the HEM method.

There are two shortcomings associated with existing studies that employ HEM. First, it cannot distinguish emissions from importers and those from exporters. Second, vast majorities of HEM studies 
in environmental research focus on describing linkages among sectors, but very few studies have attempted to examine linkages among regions. We modify HEM to address these shortcomings. Our previous study employed a modified HEM to examine the inter-industrial linkages of $\mathrm{CO}_{2}$ emissions in China (Wang et al, 2013). Here, we extend the HEM methodology to examine sectoral and regional air pollutant emissions. The modified HEM was firstly presented by Duarte et al. (2002). We added the concepts of "demand emission" and "output emission" to describe emissions from consumers and producers respectively. In this paper, we also integrated the HEM model with a Multiregional Input-Output model (MRIO) to study inter-regional embodied air pollution. Zhao et al (2015) employed a similar method to study the inter-regional linkage of $\mathrm{CO}_{2}$ emissions in 2007. Air pollutants emissions are different with $\mathrm{CO}_{2}$ emissions because of the mix of fuels used to power the economy. We also expanded the previous studies by extending the data until 2010.

Using the modified HEM model, this study aims to explore the inter-sector and inter-region air pollutants linkage in China. The major purposes of this paper are: (a) to identify the key atmospheric pollutant sectors and regions in China from the perspective of demand emissions and output emissions, respectively; and (b) to examine if those main air pollution emissions move across sectors in the same manner. The results will help to better understand the relationship between economic structure and air quality. Consequently, corresponding sector and region specific policy interventions could be designed to effectively improve the air quality.

The rest of the paper is organized as follows. Section 2 introduces the input-output method and the HEM method. The sources and processing of data are also reported in section 2, including the sector classification and aggregation. Section 3 presents the decomposition of $\mathrm{SO}_{2}, \mathrm{NO}_{\mathrm{x}}$, Soot and Dust emissions for 23 sectors and 30 regions in China, in a bid to reveal the embodied emissions flows among the sectors and regions. The conclusions and policy implications are reported in section 4 .

\section{Data Sources and Methodology}

\section{(1) IO data}

For the sectoral analysis, we used the 42-sector IO table in 2010 from the China National Bureau of Statistics. To match the classification of the emissions data, these sectors were further integrated in 23 industry sectors (see Table 1). For regional analysis, we used the 30-province MRIO table in 2010 from the Institute of Geographical Sciences and Natural Resources Research, Chinese Academy of Sciences.

(2) Emissions data

The emissions data for sectors and regions were retrieved from the national pollution census data for China (The First National Pollution Census Data Compilation Committee, 2011). For the Construction sector and Service sectors, there is no official statistics on direct emissions. We estimated air pollution emissions from these two sectors based on their primary energy (mainly coal) consumption.

\section{Table 1}

Classification of industrial sectors. 


\begin{tabular}{|c|c|}
\hline Sector classification in this study & Sector classification by the National Bureau of Statistics (2011) \\
\hline Agriculture & Farming, Forestry, Animal Husbandry and Fishery \\
\hline \multirow{2}{*}{ Fossil Fuel Mining } & Mining and Washing of Coal \\
\hline & Extraction of Petroleum and Natural Gas \\
\hline $\begin{array}{c}\text { Fossil Fuel and Nuclear Fuel } \\
\text { Processing } \\
\end{array}$ & Processing of Petroleum, Coking, Processing of Nuclear Fuel \\
\hline \multirow{4}{*}{ Metal Mining, Smelting and Pressing } & Smelting and Pressing of Ferrous Metals \\
\hline & Smelting and Pressing of Non-ferrous Metals \\
\hline & Mining and Processing of Ferrous Metal Ores \\
\hline & Mining and Processing of Non-ferrous Metal Ores \\
\hline Nonmetal Mineral Mining & Mining and Processing of Nonmetal Ores \\
\hline \multirow{4}{*}{ Food and Tobacco Products } & Processing of Food from Agricultural Products \\
\hline & Manufacture of Foods \\
\hline & Manufacture of Beverages \\
\hline & Manufacture of Tobacco \\
\hline Textile & Manufacture of Textile \\
\hline \multirow{2}{*}{ Wearing Apparel } & Manufacture of Textile Wearing Apparel, Footwear, and Caps \\
\hline & Manufacture of Leather, Fur, Feather and Related Products \\
\hline \multirow[t]{2}{*}{ Wood and Furniture } & $\begin{array}{c}\text { Processing of Timber, Manufacture of Wood, Bamboo, Rattan, Palm, and Straw } \\
\text { Products }\end{array}$ \\
\hline & Manufacture of Furniture \\
\hline \multirow{3}{*}{$\begin{array}{l}\text { Paper, Printing, Educational and } \\
\text { Sports Goods }\end{array}$} & Manufacture of Paper and Paper Products \\
\hline & Printing, Reproduction of Recording Media \\
\hline & Manufacture of Articles for Culture, Education and Sport Activity \\
\hline \multirow{5}{*}{ Chemical Products } & Manufacture of Raw Chemical Materials and Chemical Products \\
\hline & Manufacture of Medicines \\
\hline & Manufacture of Chemical Fibers \\
\hline & Manufacture of Rubber \\
\hline & Manufacture of Plastics \\
\hline Nonmetal Products & Manufacture of Nonmetallic Mineral Products \\
\hline Metal Products & Manufacture of Metal Products \\
\hline \multirow{2}{*}{ Common and Special Equipment } & Manufacture of General Purpose Machinery \\
\hline & Manufacture of Special Purpose Machinery \\
\hline Transport Equipment & Manufacture of Transport Equipment \\
\hline Electrical Equipment & Manufacture of Electrical Machinery and Equipment \\
\hline $\begin{array}{c}\text { Telecommunications and Other } \\
\text { Electronic Equipment }\end{array}$ & $\begin{array}{c}\text { Manufacture of Communication Equipment, Computers and Other Electronic } \\
\text { Equipment }\end{array}$ \\
\hline Cultural and Office Machinery & $\begin{array}{c}\text { Manufacture of Measuring Instruments and Machinery for Cultural Activity and } \\
\text { Office Work }\end{array}$ \\
\hline \multirow{2}{*}{ Power \& Gas } & Production and Distribution of Electric Power \\
\hline & Production and Distribution of Gas \\
\hline Water Production & Water Production and Supply \\
\hline Other Manufacture & Other Manufacturing \\
\hline Construction sector & Construction sector \\
\hline
\end{tabular}

Information Transmission, Computer Services and Software Industry

Wholesale and Retail Trade

Service sector

Accommodation and Catering industry

\section{Finance}

Estate

Leasing and Business Services

Research and Experimental Development 


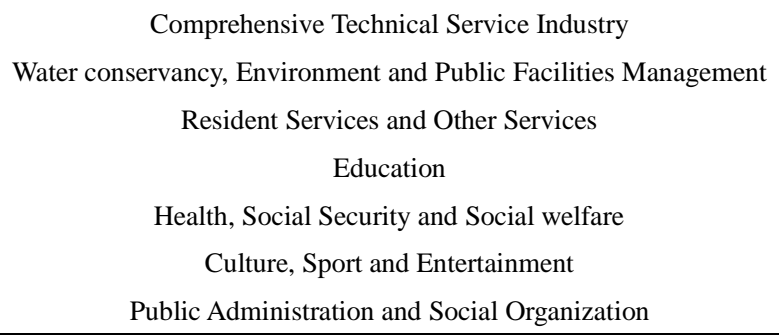

\subsection{Leontief I-O model}

Assuming that the system consists of $\mathrm{N}$ economic sectors, the fundamental equation of the Input-Output model is (Leontief, 1970),

$$
X=L Y=(I-A)^{-1} Y
$$

where $X$ is an $N \times 1$ vector/region of gross outputs (where $i=1, \ldots, N$, for each economic sector $i$ ); $Y$ is the $N \times 1$ vector/region with the each element representing final demand households, governments, capital and exports; $A=\left(a_{i j}\right)$ is an $N \times N$ matrix of input coefficients or direct requirements matrix, which describes the relationship between all sectors and regions of the economy; $a_{i j}=x_{i j} / X_{j}(i, j=1,2, \ldots, n)$ and is the ratio of direct output from sector $i$ to the output from sector $j ; I$ is the $N \times N$ identity matrix; and $L$ is the $N \times N$ Leontief inverse (or total requirements matrix) in which element $l_{i j}$ describes the amount of output from each sector $i$ per unit of final demand for the output of sector $j$ (Skelton et al., 2011; Chang, 2015).

According to Chang (2015), the distinction between imported and domestically produced inputs remained unaddressed in the input-output analysis. To assess the domestic linkages, the direct requirements coefficient matrix $A$ needs to be decomposed into domestic and imported products in SRIO table so that inter- sectoral linkage analysis can be conducted.

$$
\begin{gathered}
A=A^{d}+A^{m} \\
A^{m}=\frac{X}{X+M-E} A
\end{gathered}
$$

where $A^{d}$ and $A^{m}$ are matrices of direct requirement coefficients that measure the domestic and imported inputs, respectively; $M$ is the $N \times 1$ vector of imports; and $E$ is the $N \times 1$ vector of exports. Dietzenbacher (2005) argued that only domestically supplied inputs should be considered when analyzing linkages within an open economy; this will allow the proper evaluation of a sector's impact on the domestic economy. Consequently, a more accurate measurement of linkage indices can be determined using the domestic input-output relationship (Chang, 2015):

$$
X=\left(I-A^{d}\right)^{-1} Y^{d}
$$

The direct emissions intensity (DEI) and the total emissions intensity (TEI) are estimated as the ratio of direct emissions to total output:

$$
\begin{gathered}
D E I=\frac{W}{X} \\
T E I=D E I\left(I-A^{d}\right)^{-1}
\end{gathered}
$$

where $W$ is the total pollutant emissions of sector. TEI is the intensity row vector of the total atmospheric pollutant emissions. 


\subsection{Hypothetical extraction method (HEM)}

Developed by Schultz (1977), HEM has been widely adopted to study the impact of industry structure on industrial systems. HEM determines the importance of one sector to the entire industry system by comparing outputs of other sectors before and after the hypothetic extraction of the sector from the industrial system.

In the HEM framework, the economy system is described as

$$
\begin{aligned}
\left(\begin{array}{c}
x_{s} \\
x_{-s}
\end{array}\right) & =\left(\begin{array}{cc}
A_{s, s} & A_{s,-s} \\
A_{-s, s} & A_{-s,-s}
\end{array}\right)\left(\begin{array}{c}
x_{s} \\
x_{-s}
\end{array}\right)+\left(\begin{array}{c}
y_{s} \\
y_{-s}
\end{array}\right) \Leftrightarrow\left(\begin{array}{c}
x_{s} \\
x_{-s}
\end{array}\right) \\
& =\left(\begin{array}{cc}
\Delta_{s, s} & \Delta_{s,-s} \\
\Delta_{-s, s} & \Delta_{-s,-s}
\end{array}\right)\left(\begin{array}{c}
y_{s} \\
y_{-s}
\end{array}\right)
\end{aligned}
$$

where $s$ represents a target sector, while $-s$ represents the remaining sectors; $x=\left(\begin{array}{c}x_{s} \\ x_{-s}\end{array}\right)$ is the vector of total output; $y=\left(\begin{array}{c}y_{s} \\ y_{-s}\end{array}\right)$ is the vector of final demands; $A=\left(\begin{array}{c}x_{s} \\ x_{-s}\end{array}\right)=\left(\begin{array}{cc}A_{s, s} & A_{s,-s} \\ A_{-s, s} & A_{-s,-s}\end{array}\right)$ is the matrix of technical coefficients; and $(I-A)^{-1}=\left(\begin{array}{cc}\Delta_{s, s} & \Delta_{s,-s} \\ \Delta_{-s, s} & \Delta_{-s,-s}\end{array}\right)$ is the Leontief inverse matrix.

In the hypothetical economy, the target sector $s$ neither purchases from nor sells to the other sectors. Therefore, the hypothetical productive relationships can be expressed as:

$$
\begin{aligned}
\left(\begin{array}{c}
x^{*}{ }_{s} \\
x^{*}{ }_{-s}
\end{array}\right) & =\left(\begin{array}{cc}
A_{s, s} & 0 \\
0 & A_{-s,-s}
\end{array}\right)\left(\begin{array}{c}
x^{*}{ }_{s} \\
x^{*}{ }_{-s}
\end{array}\right)+\left(\begin{array}{c}
y_{s} \\
y_{-s}
\end{array}\right) \Leftrightarrow\left(\begin{array}{c}
x^{*}{ }_{s} \\
x^{*}{ }_{-s}
\end{array}\right) \\
& =\left(\begin{array}{cc}
\left(I-A_{s, s}\right)^{-1} & 0 \\
0 & \left(I-A_{-s,-s}\right)^{-1}
\end{array}\right)\left(\begin{array}{c}
y_{s} \\
y_{-s}
\end{array}\right)
\end{aligned}
$$

Consequently, the impact of the industry on pollution emissions can be expressed as

$$
\begin{aligned}
x-x^{*} & =\left(\begin{array}{c}
x_{s}-x_{s}^{*} \\
x_{-s}-x_{-s}^{*}
\end{array}\right)=\left(\begin{array}{cc}
\Delta_{s, s}-\left(I-A_{s, s}\right)^{-1} & \Delta_{s,-s} \\
\Delta_{-s, s} & \Delta_{-s,-s}-\left(I-A_{-s,-s}\right)^{-1}
\end{array}\right)\left(\begin{array}{c}
y_{s} \\
y_{-s}
\end{array}\right) \\
& =\left(\begin{array}{cc}
c_{s, s} & c_{s,-s} \\
c_{-s, s} & c_{-s,-s}
\end{array}\right)\left(\begin{array}{c}
y_{s} \\
y_{-s}
\end{array}\right)
\end{aligned}
$$

\subsection{Modified HEM}

Following Duarte et al. (2002), the air pollutants associated with the target sector can be decomposed into four separate components, i.e., internal emissions, mixed emissions, net backward linkage emissions, and net forward linkage emissions.

(a) Internal emissions (IE):

$$
I E=D E I_{s}\left(I-A_{s, s}^{d}\right)^{-1} y_{s}
$$

Internal emissions are the atmosphere pollutants associated with the processes within the target sector, representing the emissions embodied in the goods produced, sold, and purchased exclusively 
within the target sector.

(b) Net backward linkage emissions (NBLE):

$$
N B L E=D E I_{-s} C_{-s, s} y_{s}=D E I_{-s} \Delta_{-s . s}^{d} y_{s}
$$

Net backward linkage emissions are the net 'emission imports' by the target sector to obtain its own production demand. NBLE represents the requirements of embodied atmosphere pollutant emissions from other sectors to supply the final demand of the target sector.

(c) Net forward linkage emissions (NFLE):

$$
N F L E=D E I_{s} C_{s,-s} y_{-s}=D E I_{s} \Delta_{s .-s}^{d} y_{-s}
$$

Net forward linkage emissions are the net 'emission exports' by the target sector to support other sectors' production, i.e., NFLE represents the emissions of the target sector directly used by other sectors/regions to satisfy their final demand.

(d) Mixed emissions (ME):

$$
M E=D E I_{s} C_{s, s} y_{s, s}=D E I_{s}\left[\Delta_{s . s}^{d}-\left(I-A_{s, s}^{d}\right)^{-1}\right] y_{s}
$$

Mixed emissions are associated with the participation of both target sector $s$ and other sectors/regions $-s$ that is, the emissions embodied in the goods that are originally sold to other sectors/regions by the target sector and after being processed by other sectors/regions and consequently re-purchased by the target sector for production purposes. Therefore, ME is "mixed" because it has the dual character of both backward linkage and forward linkage (Miller and Blair, 2009).

To clearly show the roles of different sectors/regions, the concepts of demand emission $(D E)$ and output emission $(O E)$ have been proposed in our previous research (Wang et al., 2013). $D E$ is defined as the total emissions required to satisfy the demand of the target sector. $D E$ includes not only $I E$ but also all emission flows pointing to the target sector (i.e., $M E$ and $N B L E$ ). $O E$ is defined as the total emissions emitted directly by the target sector. In other words, $O E$ is the emissions embodied in the output of the target sector, which includes not only $I E$ from the target sector but also all the emission flows originating from the target sector (i.e., $M E$ and $N F L E$ ).

$$
\begin{gathered}
D E=I E+M E+N B L E \\
O E=I E+M E+N F L E \\
D E_{s}+D E_{-s}=O E_{s}+O E_{-s}
\end{gathered}
$$

\subsection{Net transferred emissions from one sector to another}

Assume that sector $t$ is one of the sectors that make up $-s$. According to the Eqs.12 and 13 on $N B L E$ and NFLE, the balance $\left(N T E_{\mathrm{s} \rightarrow \mathrm{t}}\right)$ between $N F L E_{s \rightarrow \mathrm{t}}$ and $N B L E_{t \rightarrow s}$ represents the net transferred emissions embodied in the linkages between sector $s$ and sector $t$ (Wang et al., 2013).

$$
N T E_{s \rightarrow t}=N F L E_{s \rightarrow t}-N B L E_{t \rightarrow s}=D E I_{s} \Delta_{s, t}^{d} y_{t}-D E I_{t} \Delta_{t, s}^{d} y_{s}, t \in(-s)
$$

Eq. 17 quantifies the emissions flows among sectors to show how atmospheric pollutants are transferred along the supply chain within the economic system.

2.6 Regional linkage index 
OE and NTE for regions can be calculated using to the MRIO table, where the domestic and imported inputs have already been decomposed. Therefore, ' $A$ ' can be used directly instead of ' $A$ ' in the regional linkage analysis. The Regional Linkage Index (RLI) illustrates the ratio of net transfer emissions to output emissions in a specific region and we use to compare across regions.

$$
R L I=\frac{N T E}{O E}
$$

A positive RLI indicates that the region demands emissions from other regions. A negative RLI indicates that this region emits direct emissions for other regions. $R L I$ can be used as an input in policy designed to address regional disparities in emissions.

\section{Results}

\subsection{Demand and output emissions of $\mathrm{SO}_{2}, \mathrm{NOx}$, Soot and Dust (DE and OE)}

The data in Fig. 1 (a, b, c, and d) were obtained from Eqs. 14 and 15. The IO model simply attributes the total atmospheric emissions to various sectors of the entire economic system, resulting in significant sectoral variation in terms of $\mathrm{OE}$ and $\mathrm{DE}$.

As shown in Fig. 1, the top three OE sectors for $\mathrm{SO}_{2}, \mathrm{NO}_{\mathrm{x}}$ and Soot emissions were Power \& Gas, Metal Mining, Smelting \& Pressing and Nonmetal Products sectors. These three sectors contributed to more than $60 \%$ of OE. The Power \& Gas sector dominated the total OE, accounting for 50.70\%, 61.93\% and $51.47 \%$ of the $\mathrm{SO}_{2}, \mathrm{NO}_{\mathrm{x}}$, and Soot emissions, respectively. For Dust emissions, the top three OE emission sectors were Metal Mining, Smelting \& Pressing (31.97\%), Nonmetal Products (29.11\%) and Fossil Fuel \& Nuclear Fuel Processing (7.80\%). These three sectors accounted for $68 \%$ of the total OE.

$\mathrm{SO}_{2}, \mathrm{NO}_{\mathrm{x}}$ and Soot were emitted from fossil fuel combustion, and many power plants in China were coal-fired. In 2010, $90 \%$ of $\mathrm{SO}_{2}$ emissions from industrial production activities in China were derived from the combustion of coal (Huo, 2014). New power plant development and the rapidly growing number of vehicles were responsible for the increase in $\mathrm{NO}_{\mathrm{x}}$ emissions. From 2000 to 2010, $\mathrm{NO}_{\mathrm{x}}$ emissions from power plants and transport increased by approximately $100 \%$ and $200 \%$, respectively (Wang \& Hao, 2012). As a result, the Power \& Gas sector dominated the total OE for emissions of $\mathrm{SO}_{2}, \mathrm{NO}_{\mathrm{x}}$ and Soot. However, major industrial sources for Dust emissions are quite different. Most industry dusts were derived from solid materials processing, such as mechanical crushing and grinding, mixing powders, sieving, packaging and transportation. Hence, the major Dust-contributing sectors were Metal Mining, Smelting \& Pressing and Nonmetal Products. A large amount of glass, cement, steel and iron were produced by these two industry sectors.

The main sectors contributing to DE were more dispersed. The Construction sector was the largest contributor to $\mathrm{DE}\left(27.55 \%\right.$ of $\mathrm{SO}_{2}, 29.51 \%$ of $\mathrm{NO}_{\mathrm{x}}, 33.91 \%$ of Soot, and $38.54 \%$ of Dust), followed by machinery manufacturing (21.55\% of $\mathrm{SO}_{2}, 19.54 \%$ of $\mathrm{NO}_{\mathrm{x}}, 18.7 \%$ of Soot, $25.72 \%$ of Dust) and the Service sector $\left(12.92 \%\right.$ of $\mathrm{SO}_{2}, 13.07 \%$ of $\mathrm{NO}_{\mathrm{x}}, 11.03 \%$ of Soot, $11.01 \%$ of Dust). The machinery manufacturing industries include: Common \& Special Equipment sector, Transport Equipment sector and Electrical Equipment sector. These sectors accounted for nearly $70 \%$ of DE. However, they had a small share in OE, indicating that these sectors had lower direct emissions and higher indirect emissions. 
By decomposing the output emissions (OE) and the demand emissions (DE) of atmospheric pollutants into NBLE and NFLE, it is possible to examine the characteristics of each sector in more detail. Using the NBLE (import emissions from other sectors) and NFLE (export emissions to other sectors) shares of $\mathrm{OE}$ and DE for the four air pollutants, we classified the 23 industry sectors could be classified into four categories (Table 2).

(1) Emission exporter (NFLE $>=60 \%$ and NBLE<60\%): Nonmetal Products sector was the only emissions-exporting sector for all four air pollutants. Most direct emissions in Nonmetal Products were derived from other sectors, with 92\% NFLE in OE and only 17\%-40\% NBLE in DE for four air pollutants. The Power \& Gas sector was the major emission exporter for $\mathrm{SO}_{2}, \mathrm{NO}_{\mathrm{x}}$ and Soot. The Metal Mining, Smelting \& Pressing sector, Fossil Fuel Mining sector, Fossil Fuel \& Nuclear Fuel Processing sector and Nonmetal Mineral Mining sector were the exporters of Dust emissions. The Chemical Products sector was a significant emission exporter only for $\mathrm{NO}_{\mathrm{x}}$ emission. The roles of these sectors varied for each individual air pollutant emission. However, it was worth noting that most of these sectors are basic industries, i.e., they provided necessary inputs to many other sectors. 

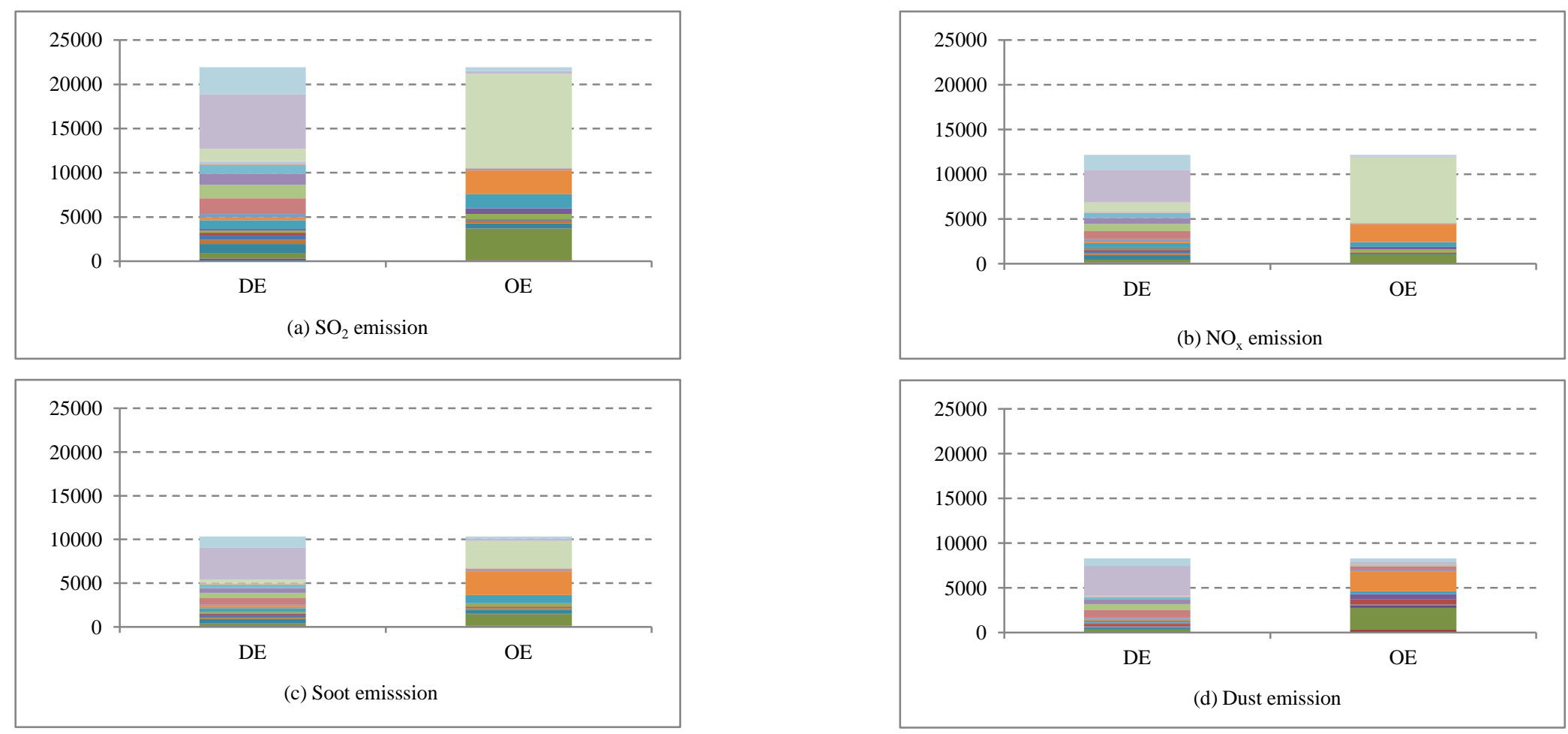

Service

- Power and gas

- Others Manufacture

- Telecommunications and other electronic equipment

- Transport Equipment

Metal Products

- Chemical Products

- Paper, Printing, educational and sports goods

Wearing Apparel

rood and Tobacco Products

Metals Mining,Smelting and Pressing

\section{E Constuction}

Water Production

Cultural and Office Machinery

- Electrical Equipment

Common and Special Equipment

Nonmetal Products

rossil fuel

Wood and Furniture

- Textile

Nonmetal Mineral Mining

Fossil fuel mining

Fig. 1. Total demand emissions and output emissions (unit: kt) 
(2) Emission exporters and importers (NFLE $>=60 \%$ and NBLE $>=60 \%$ ): The sectors in this category not only needed to intensive inputs from other sectors but also exported most of their products to other sectors. Agriculture, Metal Products and Other Manufacturers sectors belonged to this category for all four emissions. It was worth noting that some basic industries also belong to this category for some specific air pollutant emissions. For example, Fossil Fuel \& Nuclear Fuel Processing sector and Nonmetal Mineral Mining sector were not only exporters of Dust emissions but also importers of $\mathrm{SO}_{2}$, $\mathrm{NO}_{\mathrm{x}}$, and Soot emissions.

(3) Emission importers (NFLE $<60 \%$ and NBLE $>=60 \%$ ): These sectors stimulated atmospheric pollutant emissions in other sectors to satisfy their final demand, and NBLE had the largest share in DE. Construction sector, Service sector, Common \& Special Equipment sector, Transport Equipment sector, Electrical Equipment sector, Telecommunications \& Other Electronic Equipment sector, Cultural \& Office Machinery sector, and Water Production sector belonged to this category for all four atmospheric pollutants. Food \& Tobacco Products sector were importers of $\mathrm{SO}_{2}, \mathrm{NO}_{\mathrm{x}}$, and Dust, and Wood \& Furniture sector is an importer of $\mathrm{SO}_{2}$ and $\mathrm{NO}_{\mathrm{x}}$. Construction sector and Service sector emitted relatively fewer direct atmospheric pollutants than other sectors. However, if sector linkages were taken into consideration, the Construction and Service sectors required the largest amount of intermediary products from emissions-intensive inputs.

(4) Emission self-support (NFLE $<60 \%$ and NBLE $<60 \%$ ): Soot and Dust emissions were emitted directly by the Food \& Tobacco Products and Wood \& Furniture sectors from their own production and demand. IE took the largest share in $\mathrm{OE}$ and $\mathrm{DE}$, ranging from $43 \%$ to $86 \%$ in these two sectors. 
Table 2

Classification of sectors based on the decomposition of OE and DE.

\begin{tabular}{|c|c|c|c|}
\hline $\begin{array}{c}\text { (1) } \text { Emission exporters } \\
(\mathrm{NFLE}>=60 \% \text { and } \mathrm{NBLE}<60 \%)\end{array}$ & $\begin{array}{l}\text { (2)Emission exporters and importers } \\
\text { (NFLE }>=60 \% \text { and } \mathrm{NBLE}>=60 \%)\end{array}$ & $\begin{array}{c}\text { (3)Emission importers } \\
(\mathrm{NFLE}<60 \% \text { and NBLE }>=60 \%)\end{array}$ & $\begin{array}{c}\text { (4)Emission self-support } \\
\text { (NFLE<60\% and NBLE<60\%) }\end{array}$ \\
\hline Fossil fuel mining (Dust) & Fossil fuel mining $\left(\mathrm{SO}_{2}, \mathrm{NO}_{\mathrm{x}}\right.$, Soot $)$ & Food and Tobacco Products $\left(\mathrm{SO}_{2}, \mathrm{NO}_{x}\right.$, Dust $)$ & Food and Tobacco Products (soot) \\
\hline Metals Mining, Smelting and Pressing ( $\mathrm{SO}_{2}$, Soot, Dust) & Metals Mining, Smelting and Pressing $\left(\mathrm{NO}_{\mathrm{x}}\right)$ & Wood and Furniture $\left(\mathrm{SO}_{2}, \mathrm{NO}_{\mathrm{x}}\right)$ & Wood and Furniture(Soot, Dust) \\
\hline Nonmetal Mineral Mining(Dust) & Nonmetal Mineral Mining $\left(\mathrm{SO}_{2}, \mathrm{NO}_{\mathrm{x}}\right.$, Soot $)$ & Textile(all) & \\
\hline Power \& Gas $\left(\mathrm{SO}_{2}, \mathrm{NO}_{\mathrm{x}}\right.$, Soot $)$ & Power \& Gas (Dust) & Wearing Apparel(all) & \\
\hline Fossil fuel \& Nuclear fuel processing(Dust) & Fossil fuel \& Nuclear fuel processing $\left(\mathrm{SO}_{2}, \mathrm{NO}_{\mathrm{x}}\right.$, Soot $)$ & Common and Special Equipment(all) & \\
\hline Chemical Products $\left(\mathrm{NO}_{\mathrm{x}}\right)$ & Chemical Products $\left(\mathrm{SO}_{2}\right.$, Soot, Dust $)$ & Transport Equipment(all) & \\
\hline Paper, Printing, educational and sports goods $\left(\mathrm{SO}_{2}, \mathrm{Soot}\right)$ & Paper, Printing, educational and sports goods $\left(\mathrm{NO}_{\mathrm{x}}\right.$, Dust) & Electrical Equipment(all) & \\
\hline \multirow[t]{5}{*}{ Nonmetal Products(all) } & Agriculture(all) & $\begin{array}{c}\text { Telecommunications and other electronic } \\
\text { equipment(all) }\end{array}$ & \\
\hline & Metal Products(all) & Cultural and Office Machinery(all) & \\
\hline & Others Manufacture(all) & Water Production(all) & \\
\hline & & Service sector(all) & \\
\hline & & Construction sector(all) & \\
\hline
\end{tabular}




\subsection{Net transferred emissions (NTE) of pollutants}

The previous section showed that the sectors with highest OE (such as Power \& Gas, Metal Mining, Smelting \& Processing sector and Nonmetal Products sector) also had the largest NFLE share. To develop effective policies to reduce air emissions, it is imperative to identify the destinations of these NFLE.

The balance between NFLE and NBLE is the net transferred emissions (NTE). According to Eq. 17, we visualized the embodied emissions flows between the major $\mathrm{OE}$ sectors and DE sectors. $\mathrm{SO}_{2}$, $\mathrm{NO}_{\mathrm{x}}$ and Soot showed different patterns for Dust due to different sources. The Power \& Gas sector was the main source of $\mathrm{SO}_{2}, \mathrm{NO}_{\mathrm{x}}$ and Soot emissions. By contrast, Dust emissions were mainly from Metals Mining, Smelting and Pressing sector and Nonmetal Products sector. Therefore, $\mathrm{SO}_{2}$ and Dust emissions were selected as respective pollutants to show the NTE networks. Fig. 2 and Fig. 3 presented the net transferred emissions (NTE) of $\mathrm{SO}_{2}$ and dust within the network. The sectors in Fig. 2 and Fig. 3 were arranged according to their place in the supply chain, from upstream sectors to downstream sectors. These results are discussed below:

\subsubsection{NTE of $\mathrm{SO}_{2}$}

(1) Power \& Gas, Nonmetal Products sector and Metal Mining, Smelting \& Pressing sector were the primary exporters of $\mathrm{SO}_{2}$ emissions. They emitted a considerable amount of $\mathrm{SO}_{2}$ emissions (above 7000kt) to satisfy the final demand from the rest of the economy.

(2) Construction sector imported the most $\mathrm{SO}_{2}$ emissions from the other sectors. The largest inter-sector flow of $\mathrm{SO}_{2}$ emissions was from Power \& Gas sector to Construction sector (2301.3kt), followed by the flow from Nonmetal Products sector to Construction sector (1891.9kt). Construction sector accounted for $24.69 \%$ and $38.70 \%$ of the net transfer $\mathrm{SO}_{2}$ emissions from the Power \& Gas sector and Nonmetal sectors, respectively. Service sector was also a large importer of $\mathrm{SO}_{2}$ emissions. The third largest $\mathrm{SO}_{2}$ emissions flow was from Power \& Gas to Service sector (1662.9 kt).

(3) Machinery Manufacturing was also the major destination for $\mathrm{SO}_{2}$ from Power \& Gas sector, Nonmetal Products sector and Metal Mining, Smelting \& Pressing sector. Machinery Manufacturing included the Common \& Special Equipment sector, Transport Equipment sector, Electrical Equipment sector and Telecommunications \& Other Electronic Equipment sectors. In these sectors, Common \& Special Equipment sector was the largest importer and exporter. On the one hand, Common \& Special Equipment sector imported embodied $\mathrm{SO}_{2}$ emissions (1408.8kt) from Power \& Gas sector and Metals Mining, Smelting \& Pressing sector. On the other hand, it exported embodied $\mathrm{SO}_{2}$ emissions (35.5kt) to other Machinery manufacturing sectors, Service sector and Construction sectors. 


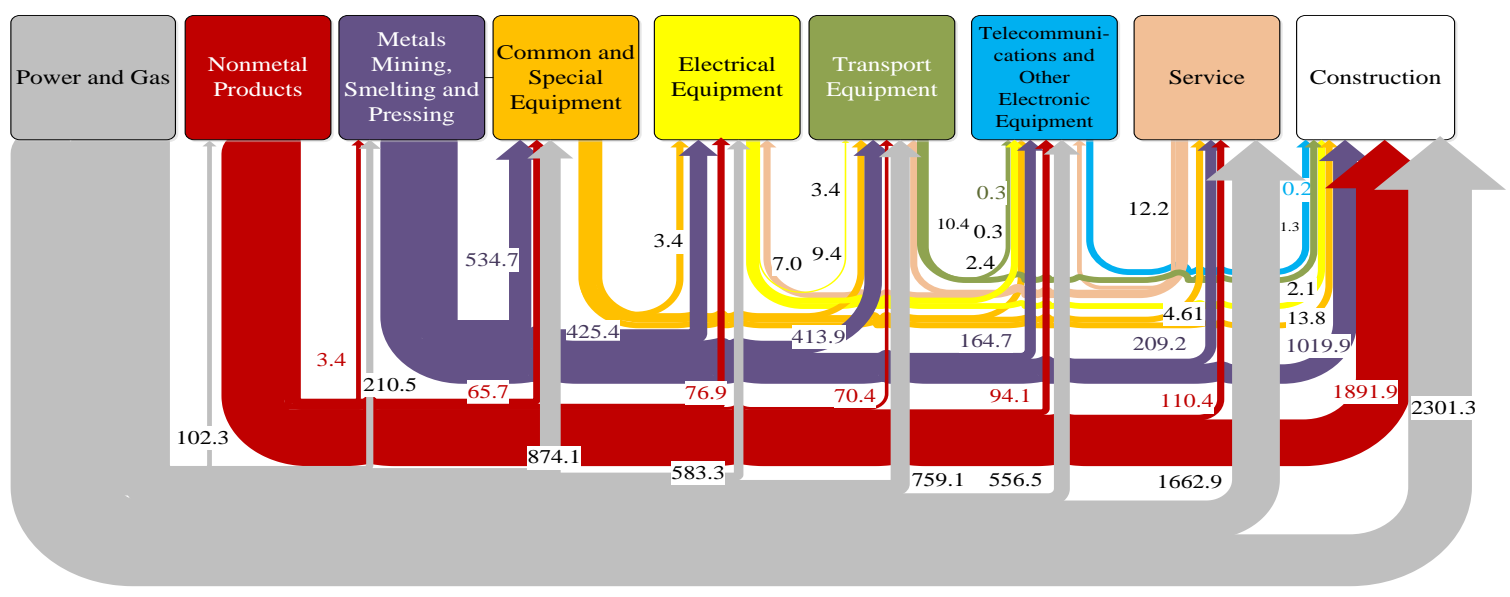

Fig. 2. Net transferred emissions (NTE) of $\mathrm{SO}_{2}$ in the $\mathrm{OE}$ network for the top $3 \mathrm{OE}$ and top $6 \mathrm{DE}$ sectors. Note: The numbers on the arrows are the amount of net $\mathrm{SO}_{2}$ transfer between the sectors connected by the arrows, with $10^{3} \mathrm{t}$. as the unit, and the arrow width represents the mass flows. Different colors represent different sectors, and the width of the arrows depicts the mass flows.

\subsubsection{NTE of Dust}

(1) As shown in Fig. 3, Nonmetal Products sector was the sector with the greatest output, followed by Metal Mining, Smelting and Pressing sector. The largest inter-sector flow of Dust emissions was from Nonmetal Products to Construction sector (1560.3kt), followed by the flow from Metals Mining, Smelting and Pressing to Construction sector (719.4kt).

(2) Common \& Special Equipment, Transport Equipment and Electrical Equipment sectors were more important for Dust emissions than the Service sector, as the Metal Mining, Smelting \& Pressing sector exported more Dust emissions to these sectors than to Service sector. The flows from Metal Mining, Smelting \& Pressing to Common \& Special Equipment, Transport Equipment and Electrical Equipment sectors were approximately 300kt. However, the Dust emissions from Metal Mining, Smelting \& Pressing to Service sector were as little as 148.7kt.

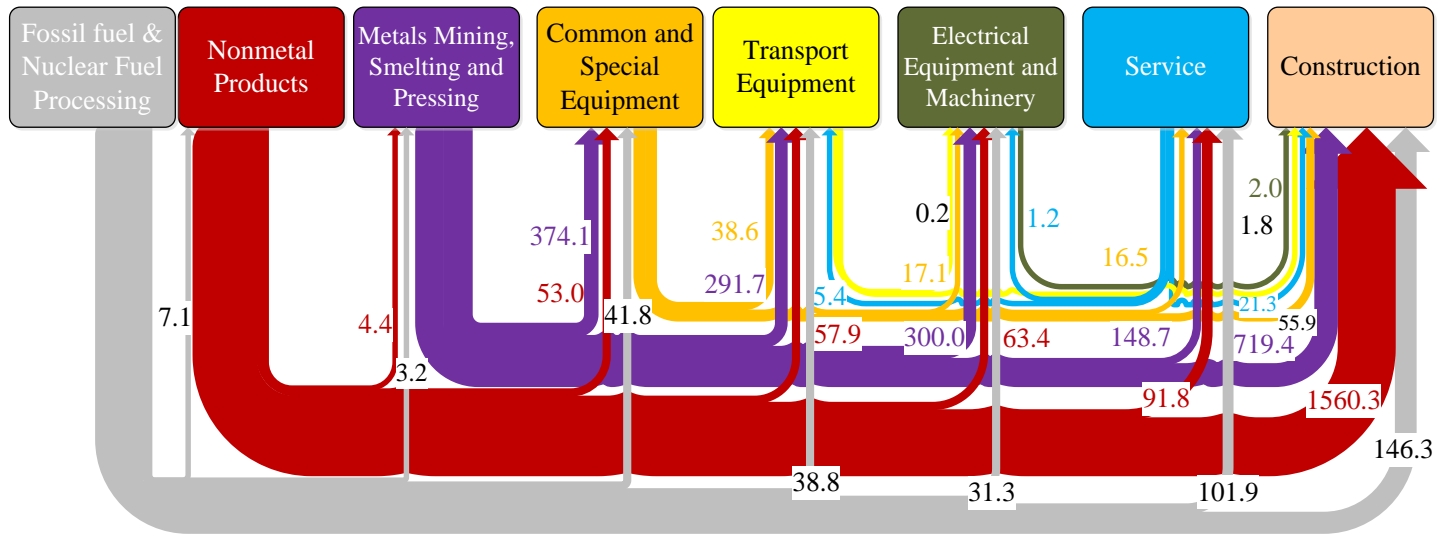

Fig. 3. Net transferred emissions (NTE) of Dust in the network of OE for the top $3 \mathrm{OE}$ and top $5 \mathrm{DE}$ sectors. ( Unit: kt) Note: The numbers on the arrows are the amount of net Dust transfer between the sectors connected by the arrows in $10^{3}$ t. and the arrow width represents the mass flows. 
These findings indicate that it is imperative to consider air pollution issues from a supply chain perspective. Related policy interventions could be more cost effective by considering the sources and sinks of pollution. For example, if the goal is to reduce the $\mathrm{SO}_{2}$ emissions, more attention should be paid to the source (e.g., reducing emissions from the Power \& Gas sector) and to the Construction sector, which is a major consumer of the Power \& Gas sector. Similarly, to control Dust emissions, efforts are required to reduce the demand from the Construction sector, which could reduce emissions from Nonmetal Products sector.

\subsection{Regional linkage}

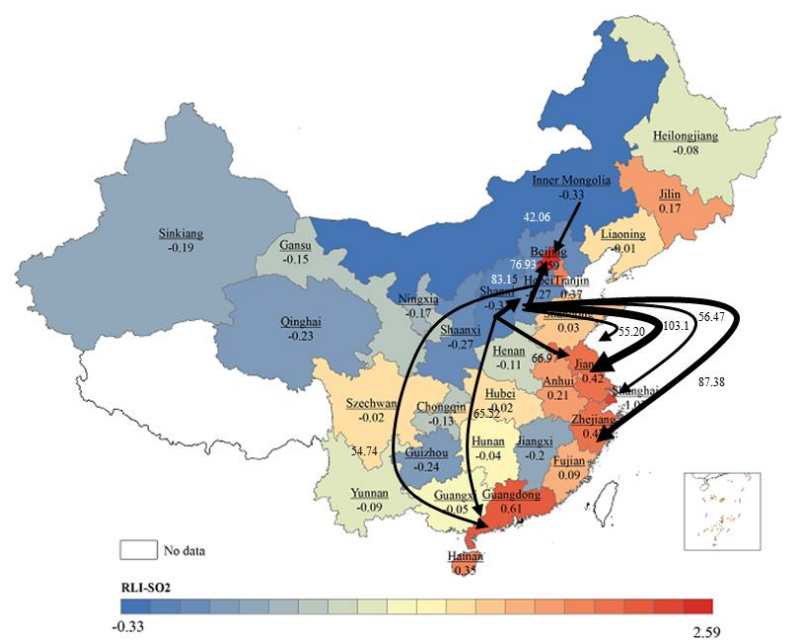

(a) $\mathrm{SO}_{2}$

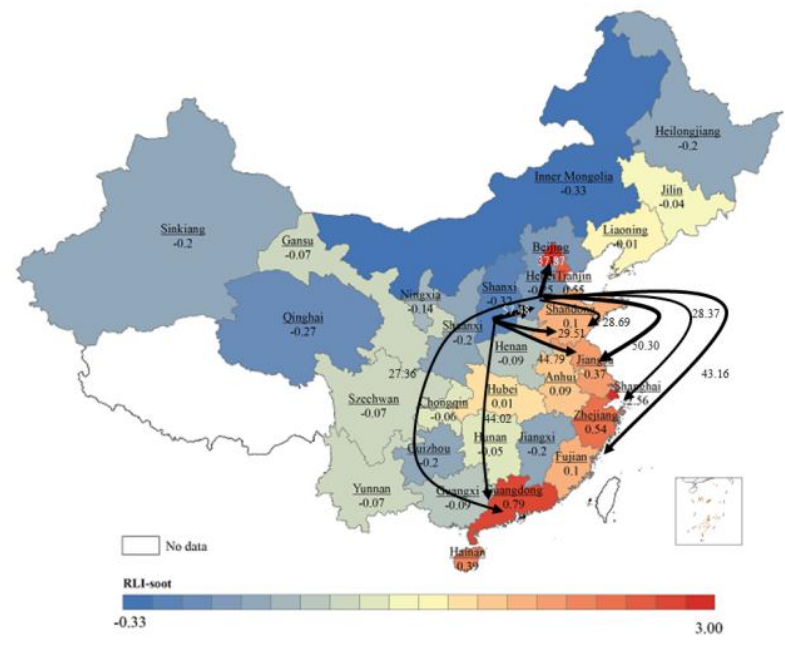

(c) Soot

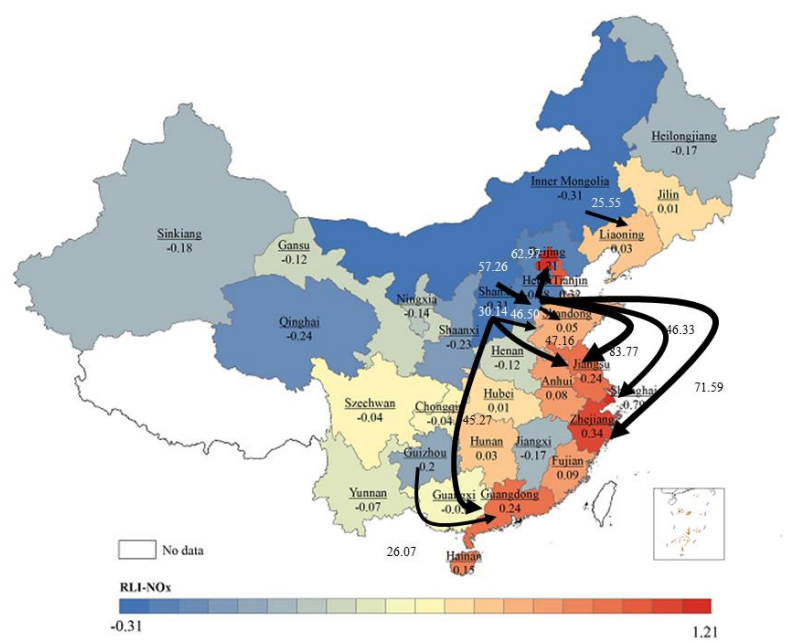

(b) $\mathrm{NO}_{\mathrm{x}}$

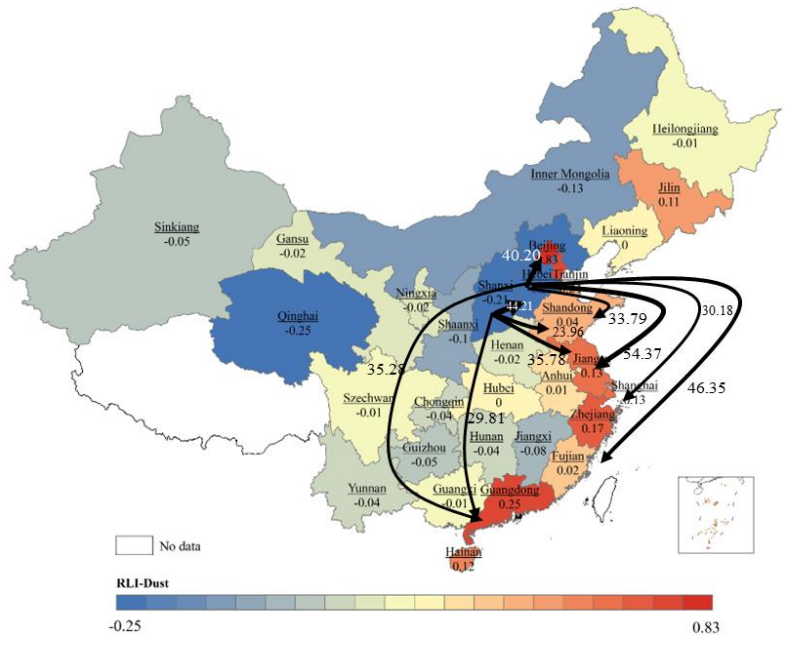

(d) Dust

Fig. 4. The regional linkage index (RLI) of 30 provinces and the top 10 embodied emission flows of NTE (kt). Note: Tibet, Hong Kong, Macau, and Taiwan are excluded from this study; these regions are colored in white.

The regional analysis of the flow of emissions is similar across all four pollutants. Major embodied air pollutants $\left(\mathrm{SO}_{2}, \mathrm{NO}_{\mathrm{x}}\right.$, Soot, and Dust) flows originated from north China to east coastal provinces of China (Fig.4). According to NTE regional value, the top 10 embodied emission flows of 
NTE among 30 provinces were mapped. Fig.4 illustrated the directions and absolute magnitudes of embodied emission flowing of four air pollutants.

As shown in Fig.4, Hebei province was the major exporter in terms of air pollutant emissions. The biggest interregional embodied $\mathrm{SO}_{2}, \mathrm{NO}_{\mathrm{x}}$ and Dust emission flows in China were from Hebei province to Jiangsu province $\left(\mathrm{SO}_{2} 103.14 \mathrm{kt}, \mathrm{NO}_{\mathrm{x}} 83.77 \mathrm{kt}\right.$ and Dust $\left.54.37 \mathrm{kt}\right)$. Moreover, it was worth noting that Hebei province was not only a major exporter but also a major importer of air pollutant emissions. The biggest Soot emission flow was from Shanxi province to Hebei province $(44.21 \mathrm{kt})$. As for $\mathrm{SO}_{2}$, the emission flow from Shanxi province to Hebei province was the second biggest with $83.15 \mathrm{kt}$. As for $\mathrm{NO}_{\mathrm{x}}$ and Dust, the emission flow from Shanxi province to Hebei province was the third biggest with $57.26 \mathrm{kt}$ and $44.21 \mathrm{kt}$, respectively. Similarly, Shanxi province was an important region providing net output of air pollutant emissions. On the one hand, Shanxi province triggered air pollutant emissions to Hebei province. On the other hand, Shanxi province exported a large quantity of air pollutant emissions to Jiangsu province, Shandong province and Guangdong province. However, significant difference existed between Shanxi province and Hebei province. Hebei province had a great deal of net inputs of air pollutants emissions from Shanxi province whereas Shanxi province did not have any NTE from other province. This is due to the fact that Shanxi province supplies power for Hebei province and other provinces. Hebei province produced basic industrial products to eastern coastal regions for manufacturing production and construction. As shown in 3.3 section, the embodied air pollutants transferred along the supply chain. This kind of sectoral linkage was also evidenced among regions.

The other central and west of China were also net exporter area for air pollutants. However, the absolute magnitudes of emission flows from these regions were smaller than the fluxes from north China to east and south coast. These regions are the undeveloped areas in China. Therefore, under the air pollution pressure from Hebei and Shanxi provinces, some highly polluted enterprises maybe move to these regions in order to mitigate the air pollution surrounding the capital city, Beijing.

From the importer perspective, Beijing, Guangdong province, Jiangsu province, Zhejiang province, and Shandong province (most of them are east and south coast area in China except Beijing, the capital city of China) are the primary destinations of air pollutant emissions transferred from not only the north China, but also other provinces. These five regions accounted for about $60 \%$ of total NTE from Hebei and Shanxi province. These destinations are the developed areas in China with high concentration of population and high level of consumption, which accounts for more than half of the country's gross domestic product. Moreover, the major industrial sectors in these provinces produce the final products for consumers. The consumption demand of these provinces trigged the embodied air pollutants flows from North of China.

The RLI showed the relative quantity for the regional comparison. According to formula (18), RLI of four air pollutants emissions were calculated for 30 provinces in China. As shown in Fig. 4, the RLI spatial characteristics for four air pollutants emissions were also similar. According to sum of RLI for four air pollutants, 30 provinces in China can be divided into five categories as shown in table 3. Hebei, Shanxi and Inner Mongolia were the main embodied air pollutants emissions exporters with sum of RLI for four air pollutants less than -1 (most blue regions shown in the Fig. 4). By contrast, the eastern coastal regions such as Beijing, Shanghai, Guangdong, Tianjin, Zhejiang, Jiangsu and Hainan 
provinces were the main embodied air pollutants emissions importers with sum of RLI for four air pollutants more than 1 (most red regions shown in the Fig. 4). Most north, central and west provinces in China emitted about 10\% 30\% output air pollutant emissions for eastern coastal provinces. This is because of the industrial regional distribution. In the exporter provinces, Power \& Gas, Nonmetal Products, Metal Mining, Smelting \& Pressing sectors and other basic industries dominated. By contrast, in importer provinces, the Construction sector, Machinery manufacturing sector and Service sector were very active as a result of booming urbanization and international trade.

Table 3

Categories for Sum of RLI for four air pollutants 30 regions

\begin{tabular}{cc}
\hline Sum of RLI & Regions \\
\hline RLI $\leq-1$ & Shanxi, Inner Mongolia, Hebei \\
$-0.1 \geq$ RLI $>-1$ & Qinghai, Shaanxi, Guizhou, Jiangxi, Ningxia, Heilongjiang, Gansu, Henan, Chongqing, \\
$0.1 \geq R L I>-0.1$ & Yunnan, Guangxi, Sichuan \\
$1 \geq R L I>0.1$ & Hunan, Hubei, Liaoning \\
RLI $>1$ & Shandong, Jilin, Fujian, Anhui \\
\hline
\end{tabular}

\section{Conclusion and Policy Implications}

HEM was employed in this study to determine the major sectors and regions responsible for atmospheric pollutant emissions in China. The air pollutant emissions $\left(\mathrm{SO}_{2}, \mathrm{NO}_{\mathrm{x}}\right.$, Soot and Dust) linkages among industrial sectors and regions were identified by using the 2010 data, which show how different economic sectors and regions interact with each other. The main conclusions are as follows:

(1) Within a Leontief production system, the Construction sector, Service sector and Machinery Manufacturing industries sector were the major demand sectors for the four atmospheric pollutants mainly because they require a considerable amount of resources, such as electricity, steel and cement. The Power \& Gas, Nonmetal Products and Metal Mining, Smelting \& Pressing sectors and other basic industries were responsible for a considerable amount of air pollutant emissions, as they provide electricity, steel and cement for demand sectors.

(2) Not all pollutant emissions moved across sectors in the same manner. For $\mathrm{SO}_{2}, \mathrm{NO}_{\mathrm{x}}$ and Soot emissions, Power \& Gas was the most significant exporter, and the major embodied emissions flows were from Power \& Gas to Construction sector. For Dust emissions, however, Power \& Gas was not the dominant exporter. Rather, Nonmetal Products and Metal Mining, Smelting \& Pressing sectors were the major exporters. A significant amount of embodied emissions flow was from Nonmetal Products sector to Construction sector. Service sector was the second-largest importer of $\mathrm{SO}_{2}, \mathrm{NO}_{\mathrm{x}}$ and Soot emissions, whereas Common\& Special Equipment was the second-largest importer of Dust emissions.

(3) Hebei province was the core exporter for embodied air pollutant emissions. Firstly, Hebei province was the largest net exporter of $\mathrm{SO}_{2}, \mathrm{NO}_{\mathrm{x}}$ and Dust emission. Moreover, the biggest Soot emission flows were from Shanxi province to Hebei province. Shanxi province was also an important region providing net output of air pollutant emissions. The main reason is that the industrial structure of Shanxi and Hebei provinces are energy (mainly coal) and basic industry (such as metal and cement) 
oriented. The primary destinations of embodied air pollutants flows were the eastern coastal provinces of China as Construction sector, Service sector and Machinery Manufacturing industries were the major economic sectors in these provinces.

Effective policy should take a more comprehensive view of the production chain into consideration. The economy system is very complex and air-quality policy needs to acknowledge this complexity. This study revealed that reduction of activities in the basic industries (major OE sectors) may pose risks on the production of the Construction sector, Service sector and Machinery Manufacturing industries (major DE sectors). This is because those major DE sectors still need inputs from the upstream industries which are the main air pollutant emissions sources.

Previous studies had proposed numerous strategies to reduce emissions, such as using cleaner fuels, transforming the industry structure, conducting end-of-pipe treatment, and so on. Based on the results of this study, the following strategies were proposed.

First, differentiated sectoral control strategies could be design using the results of this study. The government should focus on facilitating sectors that are major destinations of embodied pollutants to reduce inputs from power and heavy industries. Sector that are major sources of embodied pollutants, such as Power \& Gas, Nonmetal Products and Metal Mining, Smelting \& Pressing sectors and other basic industries, the government should support these sectors to save energy and apply end-of-pipe abatement technologies.

Second, it is imperative to establish a regional responsibility sharing mechanism for air pollutants emissions. North provinces of China emitted a large amount of air pollutants for supplying power and industrial raw materials to the east coastal provinces. Allocating responsibility for some proportions of their air pollutants emissions to east coastal provinces may coordinate interests from importers and exporters of embodied emissions.

Finally, a possible way to internalize these inter-sectoral and regional pollution flows is by means of a price signal. For sectors that contribute heavily to air-quality pollution it is difficult and costly to reduce emissions. The government could establish a price mechanism that incentivizes these heavy industries to reduce emissions, maybe by allowing costs from OE sectors to be distributed among DE sectors. Moreover, the price strategy will stimulate DE sectors to improve technology and equipment in saving energy and industrial raw materials. To some extent, price strategies can even realize regional responsibility sharing mechanism to improve the regional environmental equity. However, stringent monitoring measures need to be in place to ensure the effectiveness of any price strategy.

The findings of this study provide a useful reference for other developing regions. Many countries face a similar issue in transforming the industry structure due to growing public concern on air pollution. The methodology developed in this study could be applied to other regions to identify the most critical industry sectors in terms of pollutant emissions. Because they offer a better understanding of embodied emissions from the supply chain perspective, this study's findings provide useful data for evidence-based policy-making to reduce air pollutant emissions. Corresponding strategies could then be developed by considering the local context. Future research opportunities exist to further investigate the decomposed sectoral emissions from specific regions. In addition, the emissions from intermediate products and final consumption could be studied deeply in the context of a globalized supply chain. 


\section{Acknowledgements}

This research has been supported by the Natural Science Foundation of China (Grant no. 41571522 and no. 71673198) and the National Science Foundation of the United States of America (Grant no. 1510510). The authors gratefully acknowledge the assistance of the Institute of Geographical Sciences and Natural Resources Research, CAS for regional input-output table of China, the support of the Brook Byers Institute for Sustainable Systems, Hightower Chair, and the Georgia Research Alliance at the Georgia Institute of Technology.

\section{References}

Ali, Y., 2015. Measuring $\mathrm{CO}_{2}$ emission linkages with the hypothetical extraction method (HEM). Ecol. Indic. 54, 171-183.

Cai, J., Leung, P., 2004. Linkage measures: a revisit and a suggested alternative. Econ. Syst. Res. $16,63-83$.

Cella, G., 1984. The input-output measurement of inter industry linkages. Oxford Bulletin of Economics and Statistics 46, 73-84.

Clements, B.J., 1990. On the decomposition and normalization of inter industry linkages. Economic Letters 33, 337-340.

Chang, N., 2015. Changing industrial structure to reduce carbon dioxide emissions: A Chinese application. J. Clean. Prod. 103, 40-48.

Chen, G.Q., Guo, S., Shao, L., Li, J.S., Chen, Z.-M., 2013. Three-scale input-output modeling for urban economy: Carbon emission by Beijing 2007. Commun. Nonlinear Sci. Numer. Simul. 18, 2493-2506.

Chen J.N., 2016. Report of the State Council on the environmental situation and the completion environmental protection objectives of the year 2015. Available at http://www.npc.gov.cn/npc/xinwen/2016-04/25/content 1987688.htm

Duarte, R., Sa'nchez-Cho' liz, J., Bielsa, J., 2002. Water use in the Spanish economy: an input-output approach. Ecol. Econ. 43, 71-85.

Dietzenbacher, E., Albino, V., Kühtz, S., 2005. The Fallacy of Using US-Type Input-Output Tables. Available https://www.researchgate.net/publication/228641665_The_fallacy_of_using_US-type_inputoutput_tables

Dietzenbacher, E. and Lahr, M. 2013. Expanding extractions, Economic System Research 25(3), 341-360.

Ewing, B.R., Hawkins, T.R., Wiedmann, T.O., Galli, A., Ercin, A.E., Weinzettel, J., et al. 2012. Integrating ecological and water footprint accounting in a multi-regional input-output framework. Ecol. Indic. 23(4), 1-8.

Feng, K.S., Hubacek, K., Sun, L.X., Liu, Z., 2014. Consumption-based CO2 accounting of China's megacities: The case of Beijing, Tianjin, Shanghai and Chongqing. Ecol. Indic. 47, 26-31. 
Fujii, H., Managi, S., Kaneko, S., 2013. Decomposition analysis of air pollution abatement in China: empirical study for ten industrial sectors from 1998 to 2009. J. Clean. Prod. 59, 22-31.

Guerra, A., Sancho F., 2010. Measuring energy linkages with the hypothetical extraction method: An application to Spain. Energy Econ. 32, 831-837.

He, H., Wang Y.S., Ma J.Z, et al., 2014. Mineral dust and $\mathrm{NO}_{x}$ promote the conversion of $\mathrm{SO}_{2}$ to sulfate in heavy pollution days. Scientific Reports. 4(8), 4172.

Huo, H., Zhang, Q., Guan, D., Su, X., Zhao, H., He, K., 2014. Examining air pollution in China using production- and consumption-based emissions accounting approaches. Environ. Sci. Technol. 48, 14139-14147.

Leontief, W., 1970. Environmental repercussions and the economic structure: an input-output approach. Rev. Econ. Stat. 52, 262-277.

Ma, Q. X., Liu, Y.C. \& He, H., 2008. Synergistic effect between $\mathrm{NO}_{2}$ and $\mathrm{SO}_{2}$ in their adsorption and reaction on gamma-alumina. J. Phys. Chem. A. 112, 6630-6635.

Mi, Z.F., Pan, S.Y., Yu, H., Wei, Y.M., 2015. Potential impacts of industrial structure on energy consumption and CO2 emission: a case study of Beijing. J. Clean. Prod. 103, 455-462.

Ministry of Environmental Protection of the China. 2016. Report on the State of the Environment in China 2015. Available at http://www.cnemc.cn/publish/totalWebSite/news/news_48571.html

Miller, R.E., Blair, P.D., 2009. Input-output analysis: foundations and extensions, second ed. Cambridge University Press, New York.

Muangthai, I., Lin, SJ., Lewis, C., 2016. Inter-Industry Linkages, Energy and $\mathrm{CO}_{2}$ Multipliers of the Electric Power Industry in Thailand. Aerosol Air Qual. Res. 16(8): 2033-2047.

Peters, G.P., Hertwich, E.G., 2006. Pollution embodied in trade: The Norwegian case. Global Environ. Chang. 16, 379-387.

Pérez-Blanco, C.Dionisio, Thaler, T., 2014. An Input-Output Assessment of Water Productivity in theCastile and León Region (Spain). Water 6:929-944.

Schultz, S., 1977. Approachs to Identifying Key Sectors Empirically by Means of Input-output Analysis. J. Dev. Stud. 14, 77-96.

Singh S, Bakshi B R., 2015. Footprints of carbon and nitrogen: Revisiting the paradigm and exploring their nexus for decision making. Ecol. Indic. 53, 49-60.

Skelton, A., Guan, D., Peters, G.P., Crawford-Brown, D., 2011. Mapping flows of embodied emissions in the global production system. Environ. Sci. technol. 45, 10516-10523.

Song, Y., Liu, C., Langston, C., 2006. Linkage measures of the construction sector using the hypothetical extraction method. Construction Management and Economics 24, 579-589.

Strassert G., 1968. Zur Bestimmung strategischer Sektoren mit Hilfe von Input-Output-Modellen. Jahrbücher für Nationalökonomie und Statistik. 182:211-215.

The first national pollution census data Compilation Committee 2011. Pollution census data 
collection. China Environmental Science Press, 66-69. (in Chinese)

Wang, S., Hao, J., 2012. Air quality management in China: Issues, challenges, and options. J. Environ. Sci. 24, 2-13.

Wang, Y., Wang, W., Mao, G., Cai, H., Zuo, J., Wang, L., Zhao, P., 2013. Industrial CO2 emissions in China based on the hypothetical extraction method: Linkage analysis. Energ. Policy 62, 1238-1244.

Wei, J.C., Guo, X.M., Marinova, D., Fan, J., 2014. Industrial $\mathrm{SO}_{2}$ pollution and agricultural losses in China: evidence from heavy air polluters. J. Clean. Prod. 64, 404-413.

Yao, X.H, Chan, C.K.,Fang, M., Cadle, S.,Chan, T., Mulawa, P., He, K.B., Ye, B.M..2002.The water-soluble ionic composition of $\mathrm{PM}_{2.5}$ in Shanghaiand Beijing, China Atmospheric Environment. 36, 4223-4234.

Yuan, X., Mi, M., Mu, R., Zuo, J., 2013.Strategic route map of Sulphur dioxide reduction in China.Energ. Policy 60, 844-851.

Zhao, B., Wang, S., Wang, J., Fu, J.S., Liu, T., Xu, J., Fu, X., Hao, J., 2013.Impact of national NOx and $\mathrm{SO}_{2}$ control policies on particulate matter pollution in China. Atmos. Environ. 77, $453-463$

Zhao, Y., Zhang, Z., Wang, S., Zhang, Y., Liu, Y., 2015. Linkage analysis of sectoral $\mathrm{CO}_{2}$ emissions based on the hypothetical extraction method in South Africa. J. Clean. Prod. 103, 916-924.

Zhao, Y.H., Liu, Y., Wang, S., Zhang Z.H., Li, J.C., 2016. Inter-regional linkage analysis of industrial CO2 emissions in China: An application of a hypothetical extraction method. Ecol. Indic. 61, 428-437.

Zhou, X., Lei, K., Khu, S.T., Meng, W., 2016. Spatial flow analysis of water pollution in eco-natural systems. Ecol. Indic. 69, 310-317.

Zuo, J., Zillante, G., Wilson, L., Davidson, K., Pullen, S., 2012. Sustainability policy of Construction sector contractors: A review. Renew. Sus. Energy. Rev. 16:3010-3016. 